\title{
The effect of moderate-intensity aerobic training on serum levels of TNF- $\alpha$ and IL-6 in rats undergoing radiotherapy
}

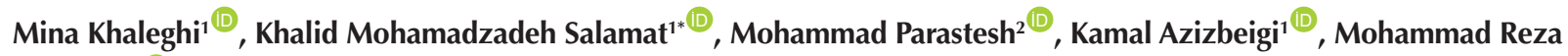 \\ Bayatiani $^{3}{ }^{\mathbb{D}}$
}

${ }^{1}$ Department of Exercise Physiology, Islamic Azad University, Sanandj Branch, Sanandaj, Iran

${ }^{2}$ Department of Sports Physiology and Pathology, Faculty of Sport Sciences, Arak University, Arak, Iran

${ }^{3}$ Department of Radiotherapy and Medical Physics, Faculty of Para Medicine, Arak University of Medical Sciences and Khansari Hospital, Arak, Iran

*Corresponding Author: Khalid Mohamadzadeh Salamat, Department of Exercise Physiology, Islamic Azad University, Sanandj Branch, Sanandaj, Iran. Tel: 09187635573, Email: kh.mohamadzadeh@gmail.com

\begin{abstract}
Background and aims: One of the main potential problems of radiotherapy (RT) in breast cancer is the increase in treatment-related inflammation. This study aimed to investigate the effect of eight weeks of moderate-intensity aerobic training (AT) on serum levels of tumor necrosis factor $\alpha$ (TNF- $\alpha$ ) and interleukin-6 (IL-6) in rats undergoing RT.

Materials and Methods: In this experimental study, 32 male rats were randomly divided into four groups of eight members including (1) healthy control (C), (2) AT, (3) RT, and (4) AT + RT groups. Rats were first anesthetized with ketamine-xylazine solution (K, 60-90 kg/mg; Z, 6-10 kg/mg) and then located on a Plexiglas plate with a thickness of $1 \mathrm{~cm}$. Photon beam RT was performed using X-rays with a dose of $11 \mathrm{~Gy}$ from an Elekta compact linear accelerator (Elekta Compact 6-MV China). AT program was performed for eight weeks, five days a week, and one session a day for 60 minutes (70-75\% of VO2max). Afterwards, one-way ANOVA was run to examine the research variables. Results: According to the results, TNF- $\alpha$ was significantly higher in the RT group compared to the $\mathrm{C}$ group $(P=0.003)$, whereas IL- 6 levels were significantly lower in the AT + RT group compared to the RT group $(P=0.001)$ and the $\mathrm{C}$ group $(P=0.027)$. Further, the levels of this cytokine were significantly lower in the AT group compared to the RT group $(P=0.006)$ and similarly in the RT group compared to the C group $(P=0.03)$.

Conclusion: RT led to an increase in pro-inflammatory cytokines; however, performing AT could only significantly reduce the IL-6 levels. Keywords: Radiotherapy, Aerobic exercise, TNF- $\alpha$, IL- 6
\end{abstract}

Received: 27 June 2021, Accepted: 29 September 2021, ePublished: December 62021

\section{Introduction}

Systemic inflammation is a risk factor for cardiovascular diseases and is considered the most common disorder and outcome of cancer treatment. Today, more than half of cancer patients receive radiotherapy (RT) treatment (1). RT is one of the main therapeutic methods used alone or in combination with other treatments. This method is invasive and not only eliminates cancer cells but also damages normal cells (2). Cardiac problems caused by RT are among the most significant potential problems of this treatment in breast cancer, affecting all three parts of the pericardium, myocardium, and coronary arteries (3).

Mild accumulation of pericardial fluid is the most prevalent type of complication after RT (4). Tumor necrosis factor $a$ (TNF- $\alpha$ ) is a proinflammatory factor involved in the local and systemic inflammation and also in the early stages of atherosclerosis until complete vessel occlusion. TNF- $\alpha$ stimulates the production of the membrane-bound interleukin-6 (IL-6) receptor (mIL-6R) in the endothelium, smooth muscle cells, and macrophages, leading to atherosclerotic plaque rupture and potential acute coronary syndrome (5). Some studies displayed a significant relationship between increased levels of TNF- $\alpha$ and the incidence of myocardial infarction (6). For example, Xu et al reported that TNF- $\alpha$ sensitized chemotherapy and RT against breast cancer cells (7).

On the other hand, IL-6 is part of a complex mixture of some chemokines and cytokines in the microenvironment of the tumor. IL- 6 acts via mIL-6R or by binding to the receptor (8). In the classical pathway, IL-6 was shown to bind to mIL-6R, which is mainly confined to a small number of cells and is responsible for homeostatic processes, acute phase response, and hematopoiesis (9). RT can also affect IL- 6 levels. In this regard, $\mathrm{Xu}$ et al reported an increase in IL-6 in samples receiving RT (10).

On the other hand, research has substantiated that regular exercise training (ET) has anti-inflammatory effects and thereby reduces the risk of heart disease (11). When levels of Interleukin 10 in the heart tissue increases, the TNF- $\alpha$ levels decrease as a result of ET, leading to reduced fibrosis and improved cardiac function (12). In addition, it has been demonstrated that aerobic physical

(C) 2021 The Author(s); Published by Shahrekord University of Medical Sciences. This is an open-access article distributed under the terms of the Creative Commons Attribution License (http://creativecommons.org/licenses/by/4.0), which permits unrestricted use, distribution, and reproduction in any medium, provided the original work is properly cited. 
activity can reduce the expression of the TNF- $\alpha$ gene expression in breast cancer in mice (13). However, Sprod et al did not report any significant changes in TNF- $\alpha$ because of ET in RT groups (14). According to the results obtained from some studies, regular aerobic training (AT) can also reduce the levels of proinflammatory cytokines such as IL-6 in tumor tissue (15). However, there are no definite results regarding the effects of ET on IL-6 and TNF- $\alpha$ levels in samples undergoing RT. Overall, given the possible effects of RT on IL- 6 and TNF- $\alpha$ levels and also the lack of previous results on the effect of aerobic exercise on IL- 6 and TNF- $\alpha$ levels in samples undergoing RT, the present study aimed to evaluate the effect of eight weeks of AT on serum levels of TNF- $\alpha$ and IL- 6 in rats undergoing RT.

\section{Materials and Methods}

\section{Study design}

This experimental study was conducted on 32 male rats in the Animal Breeding Center at Arak University of Medical Sciences. Rats were kept in 12 hours of light followed by 12 hours of dark conditions within the temperature range of $23^{\circ} \mathrm{C}$ with free access to water and food.

Accordingly, 32 rats were randomly divided into the following 4 groups with 8 members: (1) C group, which did not exercise during the study period and received no RT, (2) AT group, which performed AT for 8 weeks, (3) RT group, which underwent RT according to the protocol mentioned below, and (4) AT + RT group, which performed AT for 8 weeks and underwent RT (Figure 1).

\section{Radiotherapy}

Rats were first anesthetized with ketamine-xylazine solution ( $\mathrm{K}, 60-90 \mathrm{~kg} / \mathrm{mg} ; \mathrm{Z}, 6-10 \mathrm{~kg} / \mathrm{mg}$ ) and then located on a Plexiglas plate with a thickness of $1 \mathrm{~cm}$. This plate was finally placed on a plate with the same material and a thickness of $2 \mathrm{~cm}$, which was under the device. A plate with a thickness of 1 centimeter was located at a distance of $2 \mathrm{~cm}$ from the rat's chest to achieve $\mathrm{mpp}=3$ $\mathrm{cm}$. The distance of the source to the top Plexiglas plate

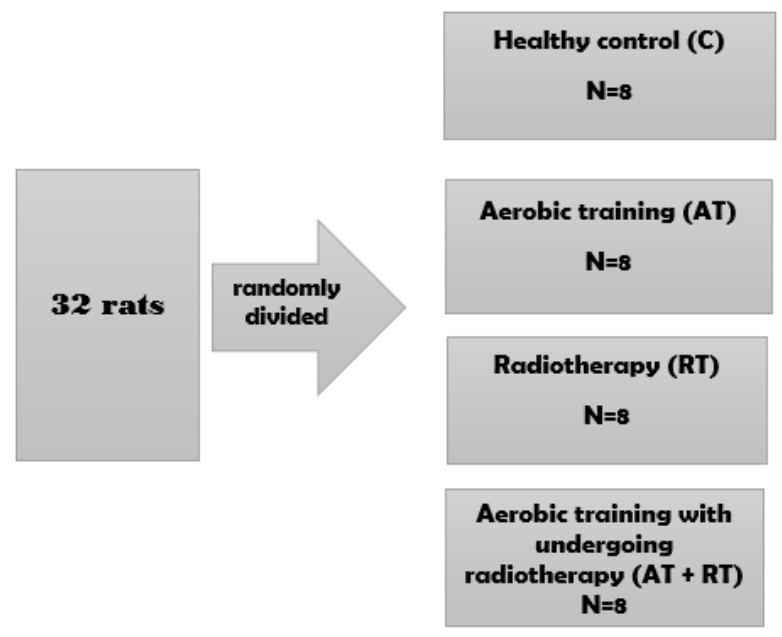

Figure 1. Schematic diagram of different groups. was considered $100 \mathrm{~cm}$. The dose of $11 \mathrm{~Gy}$ was selected according to other studies in this field. Photon beam RT was performed using X-rays with a dose of $11 \mathrm{~Gy}$ from an Elekta compact linear accelerator (Elekta Compact 6-MV China) at the RT center of Khansari hospital in Arak province, Iran (16).

\section{Aerobic training protocol}

A moderate-intensity aerobic exercise program was performed on rodents' treadmill for eight weeks, five days a week, and one session per day for 60 minutes between 8 and 12 in the morning at different speeds. After complete adaptability, the animals were placed on a treadmill with a zero-degree incline for the first week and walked at a speed of 15 meters per minute for 15 minutes (to adapt to performing training protocol). During the second to fifth weeks of training, the running speed on the treadmill increased gradually to 28 meters per minute, equivalent to $70 \%-75 \%$ of the maximum oxygen consumption. Overall, the training had moderate intensity $(8.4 \mathrm{~km} / \mathrm{wk})$. At the end of the training program, the speed inversely reduced to reach zero and cool the device (17).

Blood samples $(5 \mathrm{cc}$ ) of the rats were taken 24 hours after the last training session. After blood sampling and clotting, the samples were centrifuged whereby their serum was extracted at $3500 \mathrm{rpm}$ for 10 minutes and stored at $-70^{\circ} \mathrm{C}$ for measurement. Serum levels of TNF- $\alpha$ and IL-6 were measured using ELISA Kits (Eastbiopharm Company) for rats (made in China and licensed in the USA) according to the manufacturer's instructions.

In this study, the Shapiro-Wilk test was used to investigate the normal distribution of data. Analysis of variance (ANOVA) and Tukey's post hoc test were also conducted to examine the research variables. All investigations were performed at the $P \leq 0.05$ level using SPSS software version 21 .

\section{Results}

According to the results, the data had a normal distribution, hence parametric tests were used (Table 1). The results of one-way ANOVA represented a significant difference in the levels of TNF- $\alpha$ among the groups $(P=0.004, \mathrm{~F}=6.02$, eta squared $=0.745)$. The results of Tukey's post hoc test also revealed significantly higher levels of TNF- $\alpha$ in the RT group compared to the $\mathrm{C}$ group $(P=0.003)$; nonetheless, no significant difference was reported among the other groups (Table 2, Figure 2).

Table 1. Marker levels in all groups

\begin{tabular}{lcccc}
\hline \multirow{2}{*}{ Markers } & AT+RT & RT & AT & C \\
\cline { 2 - 5 } & Mean \pm SD & Mean \pm SD & Mean \pm SD & Mean \pm SD \\
\hline $\begin{array}{l}\text { TNF- } \alpha \\
(\mathrm{pg} / \mathrm{mL})\end{array}$ & $54.93 \pm 15.37$ & $70.66 \pm 10.68$ & $59.76 \pm 14.78$ & $39.73 \pm 9.37$ \\
$\mathrm{IL}-6(\mathrm{pg} /$ & $112.58 \pm 28.79$ & $174.46 \pm 7.81$ & $137.26 \pm 10.21$ & $143.7 \pm 11.93$ \\
$\mathrm{~mL})$
\end{tabular}


Table 2. Tukey's post-hoc test results for TNF- $\alpha$ and IL-6

\begin{tabular}{|c|c|c|c|c|c|}
\hline & Group & Group & $\begin{array}{c}\text { Mean } \\
\text { difference }\end{array}$ & SD & $P$ value \\
\hline \multirow{6}{*}{ TNF- $\alpha$} & \multirow{3}{*}{$\mathrm{AT}+\mathrm{RT}$} & AT & -4.83 & 7.39 & 0.99 \\
\hline & & $\mathrm{RT}$ & -15.73 & 7.39 & 0.27 \\
\hline & & C & 15.2 & 7.39 & 0.32 \\
\hline & \multirow{2}{*}{ AT } & RT & -10.9 & 7.39 & 0.93 \\
\hline & & C & 20.03 & 7.39 & 0.081 \\
\hline & RT & C & 30.93 & 7.39 & ${ }^{*} 0.003$ \\
\hline \multirow{6}{*}{ IL-6 } & \multirow{3}{*}{$\mathrm{AT}+\mathrm{RT}$} & AT & -24.68 & 9.73 & 0.11 \\
\hline & & RT & -61.88 & 9.73 & "0.001 \\
\hline & & C & -31.12 & 9.73 & ${ }^{*} 0.027$ \\
\hline & \multirow{2}{*}{ AT } & RT & -37.19 & 9.73 & ${ }^{*} 0.006$ \\
\hline & & C & 6.43 & 9.73 & 0.99 \\
\hline & RT & C & 30.75 & 9.73 & *0.03 \\
\hline
\end{tabular}

Note. TNF- $\alpha$ : Tumor necrosis factor $\alpha$; IL-6: Interleukin-6; C: Healthy control; AT: Aerobic training; RT: Radiotherapy; AT + RT: Aerobic training with undergoing radiotherapy; SD: Standard deviation; "Significant by Tukey's post-hoc test.

Further, the results of the one-way ANOVA statistical test demonstrated a significant difference among the groups in terms of IL-6 levels $(P=0.001, \mathrm{~F}=13.67$, eta squared $=0.672$ ). Accordingly, the results of the Tukey post hoc test showed significantly lower IL-6 levels in the AT+RT group compared to the RT group $(P=0.001)$ and the $\mathrm{C}$ group $(P=0.027)$. In addition, there was a significant difference in terms of IL- 6 levels between the AT group and the RT group $(P=0.006)$, as well as between the RT group and the $\mathrm{C}$ group $(P=0.03$, Table 2, Figure 3$)$.

\section{Discussion}

The results of this study showed a significant difference in the TNF- $\alpha$ levels between the RT group and the C group $(P=0.003)$; however, no significant difference was observed among other groups. In other words, exercise had no significant effects on TNF- $\alpha$ in neither the C nor RT groups. In this regard, Wu et al also demonstrated high sensitivity of TNF-a to RT (18). Likewise, Di Maggio et al reported an increase in TNF- $\alpha$ among RT samples in a review study (19).

Studies evidenced that cardiac stressors such as changes in hemodynamic load or lack of oxygen led to cardiac damage, and they were activated in response to proinflammatory cytokines such as TNF- $\alpha$ as the first step in the defense mechanism. Heart tissue regeneration is primarily promoted by anti-inflammatory cytokines (20, 21). However, as TNF- $\alpha$ inhibits the function of adrenergic $\mathrm{B}$ receptors, it can disable these receptors to respond to sympathetic stimuli and inhibits cardiac responses through alterations in vascular mechanical demand (22). Reduced B-adrenergic receptor response can lead to a feedback increase in sympathetic hormones, which in turn results in a feedforward increase in pro-inflammatory cytokine TNF- $\alpha$, leading to a self-perpetuating cycle that is now independent of pro-and anti-inflammatory response
$(20,21,23)$. Currently, this cycle of increased TNF- $\alpha$ inhibits B-adrenergic receptors, resulting in feedback and feed-forward cycles with subsequent deleterious signaling mechanisms, which underlie cardiac hypertrophy, deleterious regeneration, and heart failure (24). Cancer and radiation therapy seem to increase TNF- $\alpha$.

RT can induce a multilayer signaling response in mammalian cells by activating several pro-survival pathways that converge to transiently activate main transcription factors. This multilayer signaling response involves nuclear factor kappa $\mathrm{B}(\mathrm{NF}-\mathrm{\kappa} \mathrm{B})$ and signal transducers and activators of transcription (STATs). Together, these transcription factors activate a wide range of genes involved in the regulation of inflammation, apoptosis, invasion, and angiogenesis pathways, which lead to tumor cell radio-resistance $(25,26)$.

$\mathrm{NF}-\mathrm{kB}$ plays a key role in immune and inflammatory responses due to the regulation of the expression of proinflammatory cytokines and chemokines (i.e., TNF- $\alpha$, IL-1, IL-2, and IL6). RT can activate NF- $\kappa$ B through the mutated protein of ataxia telangiectasia or DNA-PK, potentially by using the MEK/ERK/p90 pathway (19).

Although the ET was supposed to reduce TNF- $\alpha$, no significant changes were reported. The results of the present study were consistent with the findings of Sprod et al (14) who did not report any significant changes in TNF- $\alpha$ due to ET in RT groups. However, Monazzami et al reported that AT can be an effective way to improve hormone levels and the TNF- $\alpha / \mathrm{IL}-12$ ratio in patients with breast cancer (27). Training intensity seems to be the reason for the insignificant changes in TNF- $\alpha$ in the present study.

The results of the present study also suggested a significantly lower IL-6 level in the AT+RT group compared to the RT group and the $\mathrm{C}$ group. Furthermore, with regard to IL-6 levels, significant differences were observed between the AT group and the RT group as well as between the RT group and the $\mathrm{C}$ group $(P=0.03)$.

$\mathrm{Wu}$ et al et al reported no increase in IL-6 in samples undergoing RT (7) while Bower et al proved its significant increase (28). In the same fashion, $\mathrm{Xu}$ et al reported that

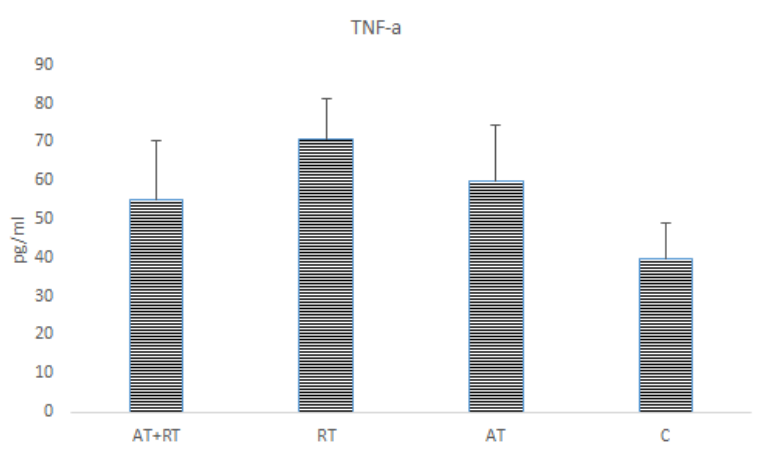

Figure 2. TNF- $\alpha$ levels. Note. TNF- $\alpha$ : Tumor necrosis factor $\alpha$; IL-6: Interleukin-6; C: Healthy control; AT: Aerobic training; RT: Radiotherapy; AT + RT: Aerobic training with undergoing; * Significant compared with C. 


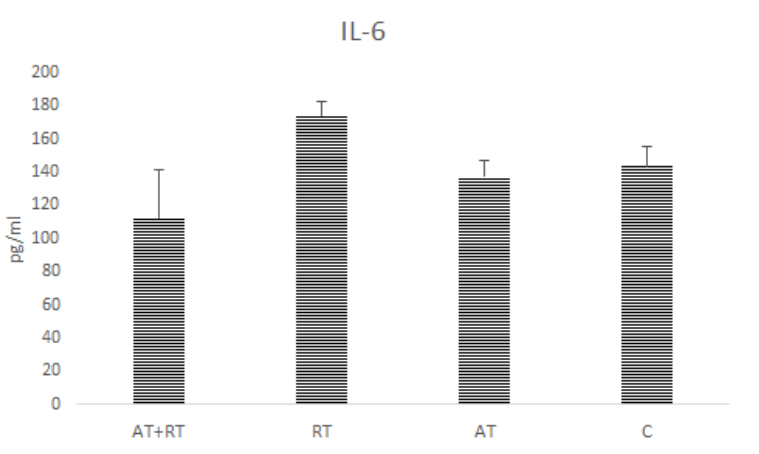

Figure 3. IL-6 levels. Note. TNF- $\alpha$ : Tumor necrosis factor $\alpha$; IL-6: Interleukin-6; C: Healthy control; AT: Aerobic training; RT: Radiotherapy; AT + RT: Aerobic training with undergoing radiotherapy; SD: Standard deviation; * Significant compared with C; * Significant compared with RT.v

increased serum IL-6 and soluble IL-6 receptors in breast cancer patients after RT were correlated with proportions of immune cells (10). High concentrations of IL-6 were associated with an increased risk of a heart attack in healthy men. In addition, IL-6 and its receptor levels had an early peak in the acute phase of myocardial infarction, possibly due to plaque instability (29). The association between high concentrations of IL- 6 and some cardiac disorders (e.g., endothelial dysfunction, arterial stiffness, and coronary atherosclerosis) has also been documented (30).

Different factors such as growth factors in the cellular environment (e.g., PGE2, NF-KB, IL-1 $\beta$, and low $\mathrm{O}_{2}$ ), lack of STAT3 inhibitors, and an increase in their active receptors resulted in an increase in the secretion of IL-6 in the tumor environment. A microRNA (miRNA) has a paracrine function, which contributes to the effect of the positive feedback loop on the IL-6/JAK/STAT cascade. Colon-derived dendritic cells secrete $29 \mathrm{~b}$ and miRNA-21, which leads to the production of IL-6, which in turn increases miRNA secretion. miRNA binds to the TLR8 receptor in immune cells and, while increasing the attack on tumor cells in vitro, produces IL-6 as well as other cytokines (31).

The results of the present study proved that AT could significantly reduce IL-6. Bianchi et al (32) and Donatto et al (33) reported that since factors such as NF-KB, PGE2, and hypoxia were involved in IL-6 activation, exercise may be effective in reducing IL-6. In this regard, Liu et al found that moderate-intensity endurance training could significantly reduce NF-KB in diabetic rats (34). In the same vein, Valenti et al reported a decrease in IL-1 antagonist receptors in tumor tissue. Likewise, Lira et al reported a decrease in PGE2 in rat cancer cells as a result of moderate-intensity aerobic exercise. Valenti et al also demonstrated that endurance exercise led to a decrease in mir-21 expression $(35,36)$. Similarly, Khori et al also evidenced that endurance exercise could reduce mir-21 in tumor tissue (37).

\section{Conclusion}

According to the results of this study, RT led to an increase in some pro-inflammatory Cytokines levels. However, moderate-intensity aerobic exercise only led to a significant reduction in IL-6 and had no significant effects on TNF- $\alpha$ levels. One of the limitations of the present study was that the amount of mir-21, NF-KB, and IL2 were not measured.

Authors' contribution

MA: Exercise training implementation, data acquisition, and manuscript drafting. KHMA: Manuscript drafting and critical revision of the manuscript. MP: Statistical analysis. KA: Manuscript drafting and critical revision. MRB: Data analysis and interpretation.

Conflict of Interests

The authors of this paper reported no conflict of interests.

Ethical Approval

The study was carried out according to all ethical codes of working with laboratory animals approved by the Ministry of Health and Medical Education (ethics code: IR.Arakmu.rec.1398.162).

\section{Acknowledgements}

This paper has been derived from the thesis conducted with code of 162262813 in the Department of Sports Physiology, Islamic Azad University, Sanandaj Branch, Sanandaj, Iran, in 2019.

Funding/Support

None.

\section{References}

1. Schover LR, van der Kaaij M, van Dorst E, Creutzberg C, Huyghe E, Kiserud CE. Sexual dysfunction and infertility as late effects of cancer treatment. EJC Suppl. 2014;12(1):41-53. doi: 10.1016/j.ejcsup.2014.03.004.

2. Hawkins PG, Kadam AS, Jackson WC, Eisbruch A. Organsparing in radiotherapy for head-and-neck cancer: improving quality of life. Semin Radiat Oncol. 2018;28(1):46-52. doi: 10.1016/j.semradonc.2017.08.002.

3. Nabiałek-Trojanowska I, Lewicka E, Wrona A, Kaleta AM, Lewicka-Potocka Z, Raczak G, et al. Cardiovascular complications after radiotherapy. Cardiol J. 2020;27(6):83647. doi: 10.5603/CJ.a2018.0120.

4. Gulati M, Mulvagh SL. The connection between the breast and heart in a woman: breast cancer and cardiovascular disease. Clin Cardiol. 2018;41(2):253-7. doi: 10.1002/clc.22886.

5. Oku T, Shimada K, Kenmotsu H, Ando Y, Kurisaka C, Sano R, et al. Stimulation of peritoneal mesothelial cells to secrete matrix metalloproteinase-9 (MMP-9) by TNF- $\alpha$ : a role in the invasion of gastric carcinoma cells. Int J Mol Sci. 2018;19(12):3961. doi: 10.3390/ijms19123961.

6. Mahmoud AH, Taha NM, Zakhary M, Tadros MS. PTEN gene \& TNF-alpha in acute myocardial infarction. Int J Cardiol Heart Vasc. 2019;23:100366. doi: 10.1016/j.ijcha.2019.100366.

7. Wu X, Wu MY, Jiang M, Zhi Q, Bian X, Xu MD, et al. TNF- $\alpha$ sensitizes chemotherapy and radiotherapy against breast cancer cells. Cancer Cell Int. 2017;17:13. doi: 10.1186/ s12935-017-0382-1.

8. Yao Y, Li R, Du J, Long L, Li X, Luo N. Interleukin-6 and diabetic retinopathy: a systematic review and meta-analysis. Curr Eye Res. 2019;44(5):564-74. doi: 10.1080/02713683.2019.1570274.

9. Johnson DE, O'Keefe RA, Grandis JR. Targeting the IL-6/ JAK/STAT3 signalling axis in cancer. Nat Rev Clin Oncol. 2018;15(4):234-48. doi: 10.1038/nrclinonc.2018.8.

10. Xu S, Yan J, Xu W, Wang Z. [Increased serum IL-6 and soluble 
IL-6 receptor in breast cancer patients after radiotherapy are correlated with proportions of immune cells]. Xi Bao Yu Fen Zi Mian Yi Xue Za Zhi. 2019;35(8):738-43. [Chinese].

11. Pedersen BK. Anti-inflammatory effects of exercise: role in diabetes and cardiovascular disease. Eur J Clin Invest. 2017;47(8):600-11. doi: 10.1111/eci.12781.

12. Calegari L, Nunes RB, Mozzaquattro BB, Rossato DD, Dal Lago P. Exercise training improves the IL-10/TNF- $\alpha$ cytokine balance in the gastrocnemius of rats with heart failure. Braz J Phys Ther. 2018;22(2):154-60. doi: 10.1016/j.bjpt.2017.09.004.

13. Lee B, Chung W. Effects of aerobic exercise on cytokine expression in a breast cancer mouse model. Iran J Public Health. 2020;49(1):14-20. doi: 10.18502/ijph.v49i1.3046.

14. Sprod LK, Palesh OG, Janelsins MC, Peppone LJ, Heckler CE, Adams MJ, et al. Exercise, sleep quality, and mediators of sleep in breast and prostate cancer patients receiving radiation therapy. Community Oncol. 2010;7(10):463-71. doi: 10.1016/ s1548-5315(11)70427-2.

15. Lee K, Qian DZ, Rey S, Wei H, Liu JO, Semenza GL. Anthracycline chemotherapy inhibits HIF-1 transcriptional activity and tumor-induced mobilization of circulating angiogenic cells. Proc Natl Acad Sci U S A. 2009;106(7):23538. doi: 10.1073/pnas.0812801106.

16. Talebi Garekani E, Mohebbi H, Kraemer RR, Fathi R. Exercise training intensity/volume affects plasma and tissue adiponectin concentrations in the male rat. Peptides. 2011;32(5):1008-12. doi: 10.1016/j.peptides.2011.01.027.

17. Dueland S, Guren MG, Olsen DR, Poulsen JP, Magne Tveit K. Radiation therapy induced changes in male sex hormone levels in rectal cancer patients. Radiother Oncol. 2003;68(3):24953. doi: 10.1016/s0167-8140(03)00120-8.

18. Wu X, Wu MY, Jiang M, Zhi Q, Bian X, Xu MD, et al. TNF- $\alpha$ sensitizes chemotherapy and radiotherapy against breast cancer cells. Cancer Cell Int. 2017;17:13. doi: 10.1186/ s12935-017-0382-1.

19. Di Maggio FM, Minafra L, Forte Gl, Cammarata FP, Lio D, Messa C, et al. Portrait of inflammatory response to ionizing radiation treatment. J Inflamm (Lond). 2015;12:14. doi: 10.1186/s12950-015-0058-3.

20. Tao L, Gao E, Jiao X, Yuan Y, Li S, Christopher TA, et al. Adiponectin cardioprotection after myocardial ischemia/ reperfusion involves the reduction of oxidative/nitrative stress. Circulation. 2007;115(11):1408-16. doi: 10.1161/ circulationaha.106.666941.

21. Rolski F, Błyszczuk P. Complexity of TNF- $\alpha$ signaling in heart disease. J Clin Med. 2020;9(10):3267. doi: 10.3390/ jcm9103267.

22. Helbig C, Weber $F$, Andreas $N$, Herdegen $T$, Gaestel $M$, Kamradt T, et al. The IL-33-induced p38-/JNK1/2-TNF $\alpha$ axis is antagonized by activation of $\beta$-adrenergic-receptors in dendritic cells. Sci Rep. 2020;10(1):8152. doi: 10.1038/ s41598-020-65072-3.

23. Shubin NJ, Pham TN, Staudenmayer KL, Parent BA, Qiu Q, O'Keefe GE. A potential mechanism for immune suppression by beta-adrenergic receptor stimulation following traumatic injury. J Innate Immun. 2018;10(3):202-14. doi: 10.1159/000486972.

24. Schumacher SM, Naga Prasad SV. Tumor necrosis factor- $\alpha$ in heart failure: an updated review. Curr Cardiol Rep. 2018;20(11):117. doi: 10.1007/s11886-018-1067-7.

25. Aravindan S, Natarajan M, Ramraj SK, Pandian V, Khan FH,
Herman TS, et al. Abscopal effect of low-LET $\gamma$-radiation mediated through Rel protein signal transduction in a mouse model of nontargeted radiation response. Cancer Gene Ther. 2014;21(2):54-9. doi: 10.1038/cgt.2013.72.

26. Lin Y, Bai L, Chen $\mathrm{W}, \mathrm{Xu} \mathrm{S}$. The NF-kappaB activation pathways, emerging molecular targets for cancer prevention and therapy. Expert Opin Ther Targets. 2010;14(1):45-55. doi: 10.1517/14728220903431069.

27. Monazzami A, Momenpur R, Alipour E, Yari K, Payandeh M. Effects of eight-week combined resistance and endurance training on salivary interleukin-12, tumor necrosis factor, cortisol, and testosterone levels in patients with breast cancer. Int J Cancer Manag. 2021;14(2):e109039. doi: 10.5812/ ijcm.109039.

28. Bower JE, Ganz PA, Tao ML, Hu W, Belin TR, Sepah S, et al. Inflammatory biomarkers and fatigue during radiation therapy for breast and prostate cancer. Clin Cancer Res. 2009;15(17):5534-40. doi: 10.1158/1078-0432.ccr-08-2584.

29. Bacchiega $B C$, Bacchiega $A B$, Usnayo MJ, Bedirian R, Singh G, Pinheiro GD. Interleukin 6 inhibition and coronary artery disease in a high-risk population: a prospective communitybased clinical study. J Am Heart Assoc. 2017;6(3):e005038. doi: 10.1161/jaha.116.005038.

30. Simon TG, Trejo MEP, McClelland R, Bradley R, Blaha MJ, Zeb I, et al. Circulating Interleukin-6 is a biomarker for coronary atherosclerosis in nonalcoholic fatty liver disease: results from the Multi-Ethnic Study of Atherosclerosis. Int J Cardiol. 2018;259:198-204. doi: 10.1016/j.ijcard.2018.01.046.

31. Patel SA, Gooderham NJ. IL6 mediates immune and colorectal cancer cell cross-talk via miR-21 and miR-29b. Mol Cancer Res. 2015;13(11):1502-8. doi: 10.1158/1541-7786.mcr-150147.

32. Bianchi RC, Ropelle ER, Katashima CK, Carvalheira JB, Lopes LR, Andreollo NA. Analysis of the physical activity effects and measurement of pro-inflammatory cytokines in irradiated lungs in rats. Acta Cir Bras. 2012;27(3):223-30. doi: 10.1590/ s0102-86502012000300004.

33. Donatto FF, Neves RX, Rosa FO, Camargo RG, Ribeiro H, Matos-Neto EM, et al. Resistance exercise modulates lipid plasma profile and cytokine content in the adipose tissue of tumour-bearing rats. Cytokine. 2013;61(2):426-32. doi: 10.1016/j.cyto.2012.10.021.

34. Liu HW, Chang SJ. Moderate exercise suppresses NF-кB signaling and activates the SIRT1-AMPK-PGC1 $a$ axis to attenuate muscle loss in diabetic $\mathrm{db} / \mathrm{db}$ mice. Front Physiol. 2018;9:636. doi: 10.3389/fphys.2018.00636.

35. Lira FS, Yamashita A, Carnevali LC Jr, Gonçalves DC, Lima WP, Rosa JC, et al. Exercise training reduces PGE2 levels and induces recovery from steatosis in tumor-bearing rats. Horm Metab Res. 2010;42(13):944-9. doi: 10.1055/s-00301267949.

36. Valenti MT, Deiana M, Cheri S, Dotta M, Zamboni F, Gabbiani D, et al. Physical exercise modulates miR-21-5p, miR-129-5p, miR-378-5p, and miR-188-5p expression in progenitor cells promoting osteogenesis. Cells. 2019;8(7):742. doi: 10.3390/ cells8070742.

37. Khori V, Amani Shalamzari S, Isanejad A, Alizadeh AM, Alizadeh S, Khodayari S, et al. Effects of exercise training together with tamoxifen in reducing mammary tumor burden in mice: possible underlying pathway of miR-21. Eur J Pharmacol. 2015;765:179-87. doi: 10.1016/j.ejphar.2015.08.031. 